\title{
AMFIC Web Data Base - A Satellite System for the Monitoring and Forecasting of Atmospheric Pollution
}

\author{
A. K. Georgoulias*,1 , I. Kioutsioukis ${ }^{1}$, P. Symeonidis ${ }^{2}$, K. Kourtidis ${ }^{1}$ \\ ${ }^{1}$ Laboratory of Atmospheric Pollution and Pollution Control Engineering, Democritus University of Thrace, 67100, Kimeria, Xanthi, Hellas. \\ ${ }^{2}$ DRAXIS Environmental Technologies, Mitropoleos 63, 54623, Thessaloniki, Hellas \\ Received 5 May 2008; Accepted 17 September 2008
}

\begin{abstract}
In this work we present the contribution of the Laboratory of Atmospheric Pollution and Pollution Control Engineering of Democritus University of Thrace in the AMFIC-Air Monitoring and Forecasting In China European project. Within the framework of this project our laboratory in co-operation with DRAXIS company will create and manage a web satellite data base. This system will host atmospheric pollution satellite data for China and for the whole globe in general. Atmospheric pollution data with different spatial resolution such as $\mathrm{O}_{3}$ and $\mathrm{NO}_{2}$ total columns and measurements of other important trace gasses from GOME (ERS-2), SCIAMACHY (ENVISAT) and OMI (EOSAURA) along with aerosol total load estimates from AATSR (ENVISAT) will be brought to a common spatial and temporal resolution and become available to the scientific community in simple ascii files and maps format. Available will also be the results from the validation procedure of the satellite data with the use of ground-based observations and a set of high resolution maps and forecasts emerging from atmospheric pollution models. Data will be available for two geographical clusters. The one cluster includes the greater area of China and the other the whole globe. This integrated satellite system will be fully operational within the next two years and will also include a set of innovative tools that allow easy manipulation and analysis of the data. Automatic detection of features such as plumes and monitoring of their evolution, data covariance analysis enabling the detection of emission signatures of different sources, cluster analysis etc will be possible through those tools. The AMFIC satellite system shares a set of characteristics with its predecessor, AIRSAT. Here, we present some of these characteristics in order to bring out the contribution of such a system in atmospheric sciences.
\end{abstract}

Keywords: Remote Sensing, Air pollution, Web based satellite system

\section{The project}

AMFIC-Air Monitoring and Forecasting In China constitutes a European Union project including 10 laboratories from Europe and China (http://www.knmi.nl/samenw/amfic/). This project aims in forecasting the atmospheric pollution in China, an area with intense development rates and therefore one of the most important polluters globally. Air monitoring and forecasting in this sensitive area is very important since the air quality in China is worse than in Europe any longer and this situation seems to become worse with time. AMFIC combines satellite measurements of trace gasses with ground-based observations and model forecasts. Satellite measurements include total column and tropospheric column estimates of $\mathrm{O}_{3}, \mathrm{NO}_{2}$ [1], $\mathrm{SO}_{2}$, formaldehyde (HCHO), $\mathrm{CO}$ and $\mathrm{CH}_{4}$ [2] along with estimates of aerosol optical parameters such as optical depth (AOD-Aerosol Optical Depth) and Ångström coefficient. The ground-based observations include ground concentration measurements and total column measurements

\footnotetext{
* E-mail address: argeor@env.duth.gr, ISSN: 1791-2377 @ 2008 Kavala Institute of Technology. All rights reserved.
}

of all the above mentioned parameters. The ground-based measurements will also be used for the validation of the satellite observations which will contribute in the evaluation and improvement of the satellite algorithms in use. Apart from measurements there will be a very important effort to detect and evaluate atmospheric pollution hot spots in China's greater area with the use of chemical transport models and forecast heavy pollution episodes. AMFIC including scientists that specialize in different areas of atmospheric sciences not only will contribute in the assessment of air pollution in China but will also establish a communication line between scientists from Europe and China.

\section{Main targets}

AMFIC's scientific team has set a number of targets that could be summarized in the expansion of European satellite remote sensing and ground monitoring of atmospheric pollution in Asia. Here, we present some of those targets.

a. Development and evaluation of satellite algorithms for the estimate in near-real time of total and tropospheric loading of atmospheric pollutants. Those algorithms 
will be evaluated through a validation procedure with the use of ground-based measurements.

b. Development of semi automated mechanisms for the creation of atmospheric pollution maps for south eastern Asia taking into account INSPIRE specifications. INSPIRE is a European Union initiative for the spatial homogenization of atmospheric pollution data allowing their easier exploitation in several sustainable development applications.

c. Assessment of air pollution in China from satellite and ground-based instruments and air quality models on local, regional and global scale and expansion of the PROMOTE GMES service on a larger scale.

d. Creation of a state-of-the-art web data base that will allow scientists all over the world to come across and analyze atmospheric pollution data not also for the greater area of China but also for the whole globe.

\section{The contribution of Laboratory of Atmospheric Pollution and Pollution Control Engineering}

Within the framework of AMFIC project our laboratory in cooperation with DRAXIS Environmental Technologies company will create and manage the AMFIC web satellite data base which will host the results and findings of the project and will allow the online analysis and manipulation of data. This data base aims in a) the exploitation of satellite and ground-based data along with model results, b) showing how to use satellite data in the investigation and monitoring of procedures connected with transcontinental air pollution. Our main obligations are summarized below:

a. Spatial and temporal homogenization of data to allow their easier concurrent analysis, plotting and mapping.

b. Fixing and maintaining the web data base.

c. Development of a number of tools that will allow the easy manipulation and analysis of the data. Those tools will enable automatic detection of features such as plumes and monitoring of their evolution, data covariance analysis enabling the detection of emission signatures of different sources, cluster analysis and export of data in different formats.

The data that will be hosted in the data base are presented below:

a. $\mathrm{O}_{3}, \mathrm{NO}_{2}, \mathrm{SO}_{2}$ total and tropospheric columns and $\mathrm{HCHO}$, $\mathrm{CO}, \mathrm{CH}_{4}$ total columns from GOME-Global Ozone Monitoring Experiment [3] aboard ERS-2, SCIAMACHY-Scanning Imaging Absorption Spectrometer for Atmospheric CHartographY aboard ENVISAT and OMI-Ozone Monitoring Instrument [4] aboard EOS-AURA, aerosol optical parameters estimates such as optical depth (AOD-Aerosol Optical Depth) Ångström coefficient from AATSR aboard ENVISAT. The data will be available for two geographical clusters (China's greater area and whole globe) in simple ascii files and maps format. b. Ground-based observations from CIMEL photometers, BREWER sunphotometers and ozonesondes and ground level concentration measurements.

c. Model forecasts both on local scale (AURORA-even $4 \mathrm{~km}$ resolution) and regional scale (TM5- $0.25^{\circ} \times 0.25^{\circ}$ resolution).

\section{The predecessor of AMFIC web data base}

AMFIC web data base will be developed with the same standards as another web based satellite system called AIRSAT (http://www.satellite-earth-simulator.com/). Atmospheric pollution data hosted on this data base refer to two geographical clusters. The first cluster includes the region of Thrace [GRID $1(22 \mathrm{E}, 43 \mathrm{~N}, 28 \mathrm{E}, 39 \mathrm{~N})$ ] while the second cluster includes the greatest part of Europe [GRID 2 $(-24 \mathrm{E}, 72 \mathrm{~N}, 32 \mathrm{E}, 32 \mathrm{~N})]$. AIRSAT [5], [6] includes satellite data from Earth Probe TOMS-Total Ozone Monitoring Instrument aboard Earth Probe, SCIAMACHY, GOME and MODIS-MOderate resolution Imaging Spectroradiometer aboard EOS-TERRA and meteorological data from NCEP/NCAR reanalysis project. The satellite data hosted include $\mathrm{O}_{3}$ and $\mathrm{NO}_{2}$ total columns, aerosol optical depth over oceans, cloud optical depth, cloud top temperature, optical depth over land and oceans, atmospheric water vapor, chlorophyll total load and sea surface temperature for day and night. The meteorological data include surface temperature, relative humidity, sea level and ground level pressure, wind speed and precipitation from NCEP/NCAR reanalysis project models. Those models assimilate data from 1948 until today to forecast a number of meteorological parameters covering the whole globe. In the following section a series of AIRSAT and AMFIC innovative common features are presented.

\section{AMFIC web data base innovations}

Here, we present some of the capabilities that the AMFIC satellite system will offer to the users. We give some examples from the innovations that AMFIC shares with AIRSAT. First of all we present the way of selecting data of specific time period and geographical area and the format of the data finally obtained by the user. In the following figures the way of requesting and analyzing Earth Probe TOMS total ozone data for the $\left(-24^{\circ} \mathrm{E}, 72^{\circ} \mathrm{N}, 32^{\circ} \mathrm{E}, 32^{\circ} \mathrm{N}\right)$ area and for the time period 17-31/10/2004 is exhibited. In Fig.1, the user requests the above mentioned data while in Fig.2 and Fig. 3 one can see the results of the request. In Fig. 2 there is a map with the ozone total column for the first day $(17 / 10 / 2004)$ for the region of interest. By pressing the proper button the corresponding maps for the rest of the days (18-31/10/2004) show up as an animation. Moreover, in Fig. 3 it is shown that below the animation screen a set of thumbnails of these maps for the period (17-31/10/2004) can be found. By pressing on each thumbnail the map shows up on the screen above. Below each thumbnail there is a link. By pressing this link one can download the data presented on the corresponding map in $1^{\circ} \times 1^{\circ}$ resolution in simple ascii file format. For each map exhibited on the screen, the user can select a spot with the mouse just by clicking on the map or by setting specific coordinates in the fields between the screen and the thumbnails area. By following one of those 
two options the user will have a time series (plot and data) for the initially selected time period (17-31/10/2004). In Fig.4, the plot of the total ozone time series for the region of Xanthi, Greece $\left[41.133^{\circ} \mathrm{N}, 24.883^{\circ} \mathrm{E}\right]$ that emerged with the way described above is shown. Below the plot there is a link from which the user can download the corresponding data.

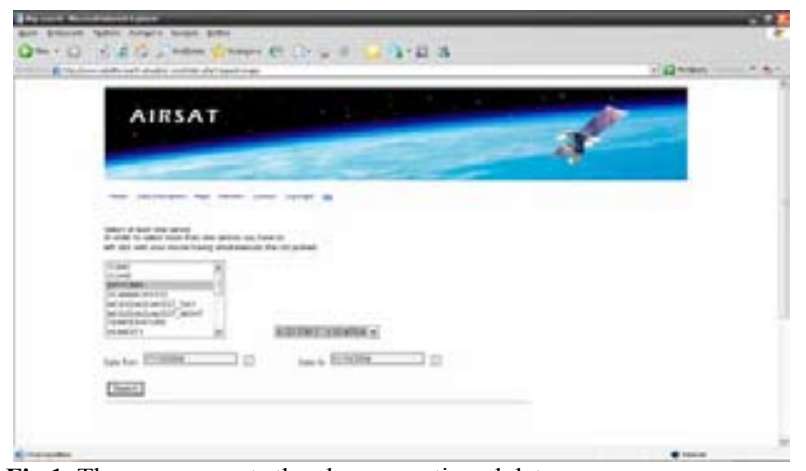

Fig 1. The user requests the above mentioned data

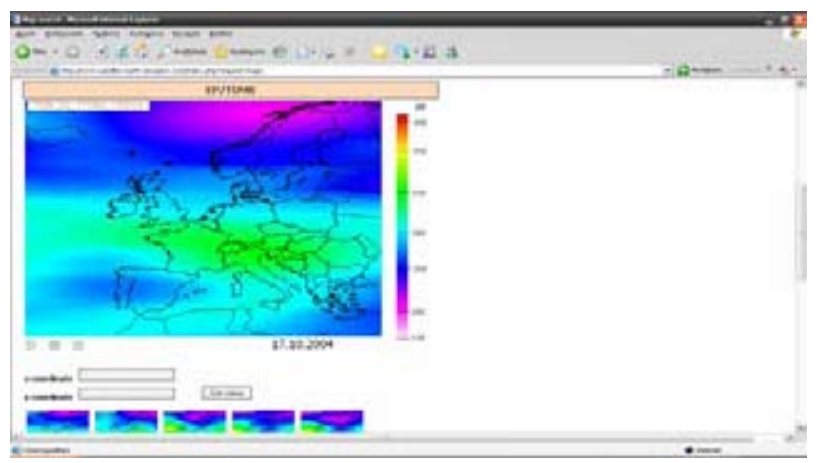

Fig 2. The results of the request

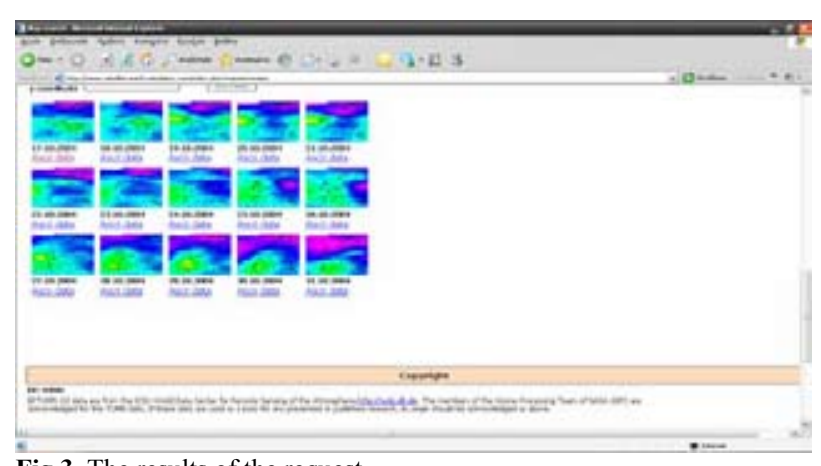

Fig 3. The results of the request

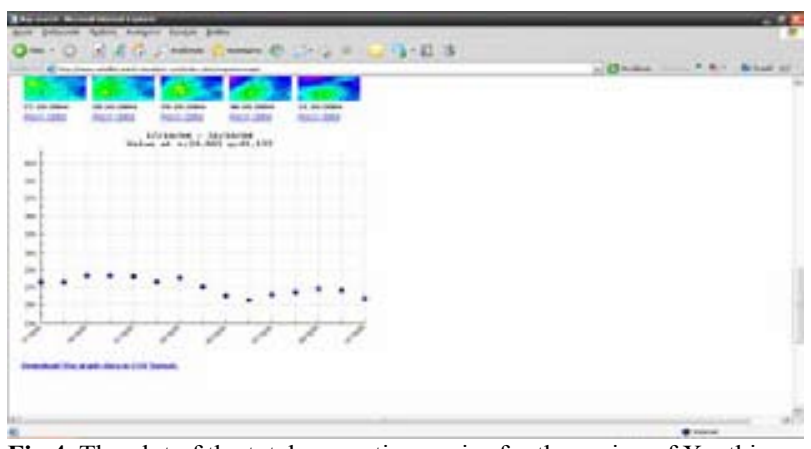

Fig 4. The plot of the total ozone time series for the region of Xanthi, Greece
Below we present some examples of the statistical exploitation of data that will be possible through AMFIC data base. In Fig.5a one can see the result of the statistical analysis of Sea Level Pressure and Relative Humidity for the greater part of Europe (GRID 2) for the year 2006. In Fig.5a, a $60 \%$ covariance of sea level pressure and relative humidity for the year 2006 is presented. This means that the specific pattern of sea level pressure in the upper figure is connected at a satisfying level with the specific pattern of the relative humidity in the lower figure. In Fig.5b, we can see a set of contour maps with the correlation of Precipitation above the region of Thrace, Greece and large scale Sea Level Pressure for several temporal lags for the period $1 / 2004-12 / 2005$. The bars on the right of each diagram represent the square of correlation coefficient, R. This means for example that the pressure system above the region of Italy shown in the first figure presents a statistically important negative correlation with the precipitation above the region of Thrace.
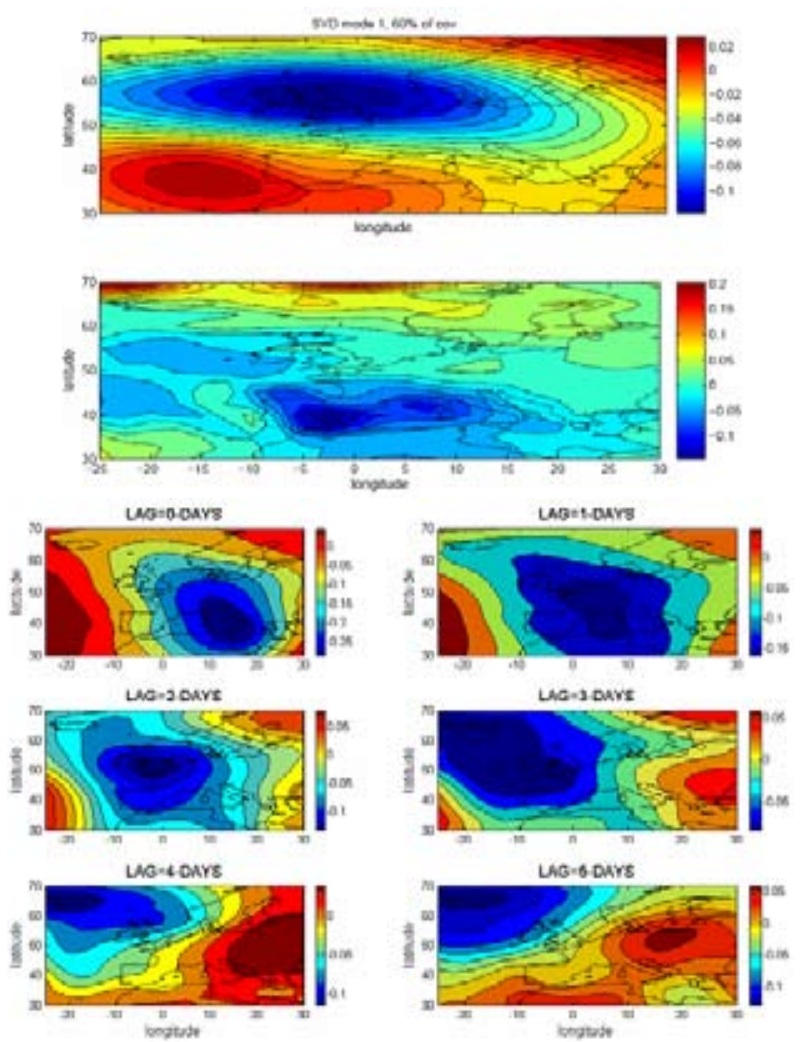

Fig. 5a \& 5b. The result of the statistical analysis of Sea Level Pressure and Relative Humidity a set of contour maps with the correlation of Precipitation above the region of Thrace, Greece

Moreover, the AMFIC data base will offer a set of maps with back-trajectories calculated with the HYSPLIT model and pollution hot spots such as lignite burning power plants (Fig.6), results from back-trajectory cluster analysis and ascii files with information on back-trajectories that passed over major sources before arriving over the region of interest. Finally, the data base will offer an automatic plume detection tool. This will be possible via chromatic analysis of images with the use of local chromatic histograms (Fig.7). 

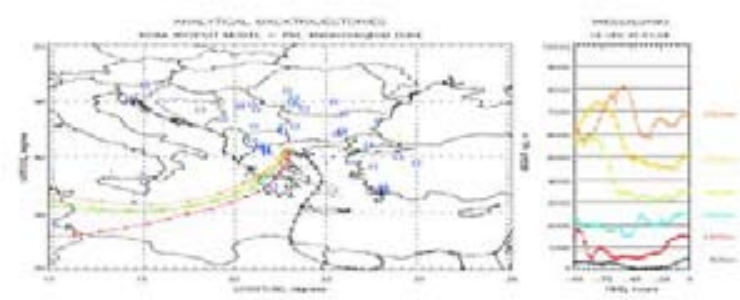

Fig 6. Results from back-trajectory cluster analysis and ascii files with information on back-trajectories that passed over major sources before arriving over the region of interest

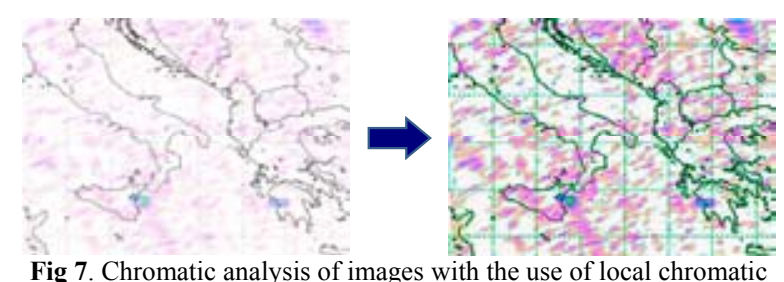
histograms

\section{Summary}

AMFIC web data base will be the product of the contribution of Laboratory of Atmospheric Pollution and Pollution Control Engineering in AMFIC-Air Monitoring and Forecasting in China. This state-of-the-art satellite system will host air pollution satellite data for the greater area of China and the whole globe, ground-based observations and model forecasts for the region of China. Moreover, a set of innovative tools will allow the online statistical analysis of the data. Within the next two years AMFIC will become a center of attraction for scientists from all the branches of atmospheric sciences and will contribute in bringing out the usefulness of satellite remote sensing in pollution assessment.

\section{References}

1. R.J. van der A, D.H.M.U. Peters, H. Eskes, K.F. Boersma, M. Van Roozendael, I. De Smedt, and H.M. Kelder, Detection of the trend and seasonal variation in tropospheric $\mathrm{NO}_{2}$ over China, J. Geophys. Res., 111, D12317, doi:10.1029/2005JD006594 (2006).

2. M. Buchwitz, R. de Beek, S. Noel, J.P. Burrows, H. Bovensmann, H. Bremer, P. Bergamaschi, S. Körner, M. Heimann, Carbon monoxide, methane and carbon dioxide columns retrieved from SCIAMACHY by WFM-DOAS: year 2003 initial data set, Atmos. Chem. Phys., 5, 1943-1971 (2005).

3. J.P. Burrows, M. Weber, M.Buchwitz, V. Rozanov, A. Ladstätter Weißenmayer, A. Richter, R. DeBeek, R. Hoogen, K. Bramstedt, K. Eichmann, and M. Eisinger, The Global Ozone Monitoring Experiment (GOME): Mission Concept and First Scientific Results, J. Atmos. Sci., 56, 151-175 (1999).
4. P.F. Levelt, E. Hilsenrath, G.W. Leppelmeier, G.H.J. van den Oord, P.K. Bhartia, J. Tamminen, J.F. de Haan and J.P. Veefkind, Science Objectives of the Ozone Monitoring Instrument, IEEE Trans. Geo. Rem. Sens., 44, 5, 1199-1208, doi:10.1109/TGRS.2006.872336 (2006).

5. P.E. Symeonidis, A. Kokonozi, K. Kourtidis and E. Kosmidis, Use of Remote Sensing Data and GIS Technologies for Environmental Modeling: The AIRSAT project, International Conference on Environmental Applications and Distributed Computing, EADC'2006, Bratislava, Slovak Republic, October 16-17 ( 2006).

6. P.E. Symeonidis, A. Kokonozi, K. Kourtidis and E. Kosmidis, AIRSAT project: a demonstration of the use of remote sensing data for environmental modeling, ESA-EUSC 2006: Image Information Mining for Security and Intelligence, EUSC, Torrejon air base - Madrid, Spain, November 27-28 (2006). 